\title{
Complementary Regimes of Solar and Wind Energy in Serbia
}

\section{Petar Gburčik, Verica Gburčik, Milivoj Gavrilov, Vladimir Srdanović, Sreten Mastilović}

\begin{abstract}
Solar and wind energy meteorological parameters are inherently characterized by an expressive annual variability. In Serbia, the maximum availability of wind energy typically occurs during winter while the solar energy peaks occur in summer. On the other hand, the energy consumer requirements are highest during winter. The natural potential of solar energy could cover, in theory, all consumer demands even if the solar energy would be the only resource used, but it would necessitate building of capacities that in the period of minimum energy output would be sufficient to cover the maximum consumer demands. The solar and wind energy meteorological parameters are also inherently characterized by an expressive diurnal and day-to-day variance. The energy output with a smaller amplitude in the daily and annual patterns would be obtained by application of complementary regimes of solar and wind energy. The complementarity of solar and wind energy is especially pronounced in the Koshava-wind region of Serbia. The characteristic profiles of these two energy resources are presented in this study on the analytic level (broader scale), as well as on the application level at the referent measurement sites.
\end{abstract}

Key words: Solar energy, Wind energy, Renewable resources, Complementarity of energy

1 Center for Multidisciplinary Studies, University of Belgrade 11030 Belgrade, Kneza Višeslava 1, www.cms.bg.ac.yu, gburcikv@eunet.yu

\section{Introduction}

The average rate of increase of wind power utilization in EU over the past ten years stayed at $32 \%$. Rated by the wind power capacity installed in 2005, the top five countries on the European energy market were: Germany $(1,808 \mathrm{MW})$, Spain $(1,764 \mathrm{MW})$, Portugal $(500 \mathrm{MW})$, Italy (452MW), and UK (446MW), (EU, 2006a). Countries with the highest total installed capacity are Germany $(18,428 \mathrm{MW})$ and Spain $(10,027 \mathrm{MW})$, (EWEA, 2006).

The European Wind Power Association (Mays, 2006) has launched „No Fossil Fuels" campaign to show that wind power alone can supply over one-fifth of the needs for electric energy in Europe by 2010 This would secure an effective solution to the energy crisis Europe is faced with, thus eliminating the uncertainty created by the rising oil prices on the market. Awerbuch (2006) predicts that the present generation of wind turbines will produce electricity that would be cheaper than that produced from natural gas.

Similarly, there are advances in utilizing solar energy (EU, 2006b), particularly by using photovoltaic cells, where panels installed on the roofs of individual houses are directly connected to the electricity grid.

The crucial question is whether Serbia has adequate potentials to actively follow these European trends? Henceforth we present our research results and argue that Serbia has considerable solar and wind energy potential and, what is particularly convenient, that the two (energy forms) complement each other seasonally.

\section{Renewable Resources}

Fossil fuels are, worldwide, the most important energy resource at the moment, but at the same time they are the main source of air pollution and excessive heating of the lower tiers of the atmosphere. Two main reasons for abandoning longterm reliance on fossil fuels as the primary energy resource are: degrading air quality along with the climate change caused by the elevated air temperature and the lim- ited fossil fuel resources. Similarly, apart from the nuclear waste problem, limited resources of the uranium make nuclear energy unlikely sustainable substitute for the fossil fuels.

Renewable energy resources (such as solar radiation, biomass, wind and hydro energy) represent various combinations of the solar energy and water presence in the atmosphere, and are, therefore, alternatively referred to as climatic resources (Gburčik P. et al, 2004). These resources were fundamental to all civilizations thus far.

The fossil fuels and nuclear energy, as non-renewable energy resources, emerged only within the last two centuries. High energy concentration (density), characteristic of these resources, resulted in significant acceleration in industrial production; however, there were also adverse consequences for the environment and human health.

Physical rationale of sustainable development is founded on the physics of the atmosphere within which climatic resources, indispensable for both the origin and sustainability of life on Earth, are embedded. Processes are unsustainable or unstable whenever equilibrium, often a very subtle one, is disturbed. At the moment we witness a disturbed equilibrium of the total ozone and carbon dioxide in the atmosphere, mainly as a consequence of the use of fossil fuels. The excessive energy use today might just be the beginning of the adventurous new era of unsustainable development, (UNEP, 2002a).

Amount of energy available from climatic resources is generally underestimated, and consequently it is erroneously assumed that climatic resources can only provide for modest quantities of „alternative energy." Contrary to these "popular misconceptions", the measurements indicate that energy delivered by the Sun to the surface of the Earth is 15,00o times that of the actual world energy consumption. The fact is that solar and wind energy potential is many times that of the present day energy demands. In the countries with political determination to pursue the use of energy 
from renewable resources, abandoning the use of fossil fuels appears to be a realistic perspective, (EU, 2003).

\section{Solar and Wind Energy in Serbia}

„The Study of Energy Potential of Serbia for Utilizing Solar Radiation and Wind Energy" was completed in 2004 (Gburčik P. et al., 2004) within the framework of the Serbian National Energy Efficacy Program, supported by the Ministry of Science and Environmental Protection. Based on the results and the reviews of this original study, the Ministry has requested a sequel study whose goal is to determine spatial-temporal distribution of the solar and wind energy potential, that is, to create an atlas of the solar and wind energy in Serbia.

Some results from our ongoing research project, presented herein, demonstrate that Serbia has considerable renewable energy resources characterized by seasonal complementarity of solar and wind energy potentials. It has been established that average annual energy influx of global solar radiation on horizontal surface in Serbia is $1,387 \mathrm{kWh} / \mathrm{m}^{2}$. Figure 1 shows spatial distribution of solar energy during the vegetation period (April-September).

Daily amounts of solar energy during the vegetation period range from $4.9 \mathrm{kWh} /$ $\mathrm{m}^{2}$, on the west, to $5.7 \mathrm{kWh} / \mathrm{m}^{2}$, on the southeast of Serbia. The lowest measured values in Serbia are similar to the highest ones measured in Austria and Germany, which are leading countries in solar energy utilization. It has been determined that values of solar energy parameters in mountainous region of Western Serbia are low. This is a consequence of the increased daytime cloudiness characteristic of the region over the summertime. Knowing the amount of solar energy received over the vegetation period is also important for calculating the potential for biomass production.

The European Wind Atlas (CEC, 1989) shows maps of average wind power measured in power density units $\left(\mathrm{W} / \mathrm{m}^{2}\right)$. For comparison, the wind power map for Serbia is presented here. In studies mentioned above, maps have been created that depict the total amount of energy in $\mathrm{kWh} / \mathrm{m}^{2}$ as well.

The calculated wind power in the windiest parts of Serbia is comparable to the wind power of some of the windiest parts of Europe, situated in countries which are, not surprisingly, also the most active investors into wind energy facilities. Notably, these regions are in the northern Germany and south from Pyrenees in Spain, (CEC, 1989).

Figure 2 shows map of average wind power at the height of $100 \mathrm{~m}$. The Koshava-wind region, characteristic of the Danube river valley between the towns Slanka-

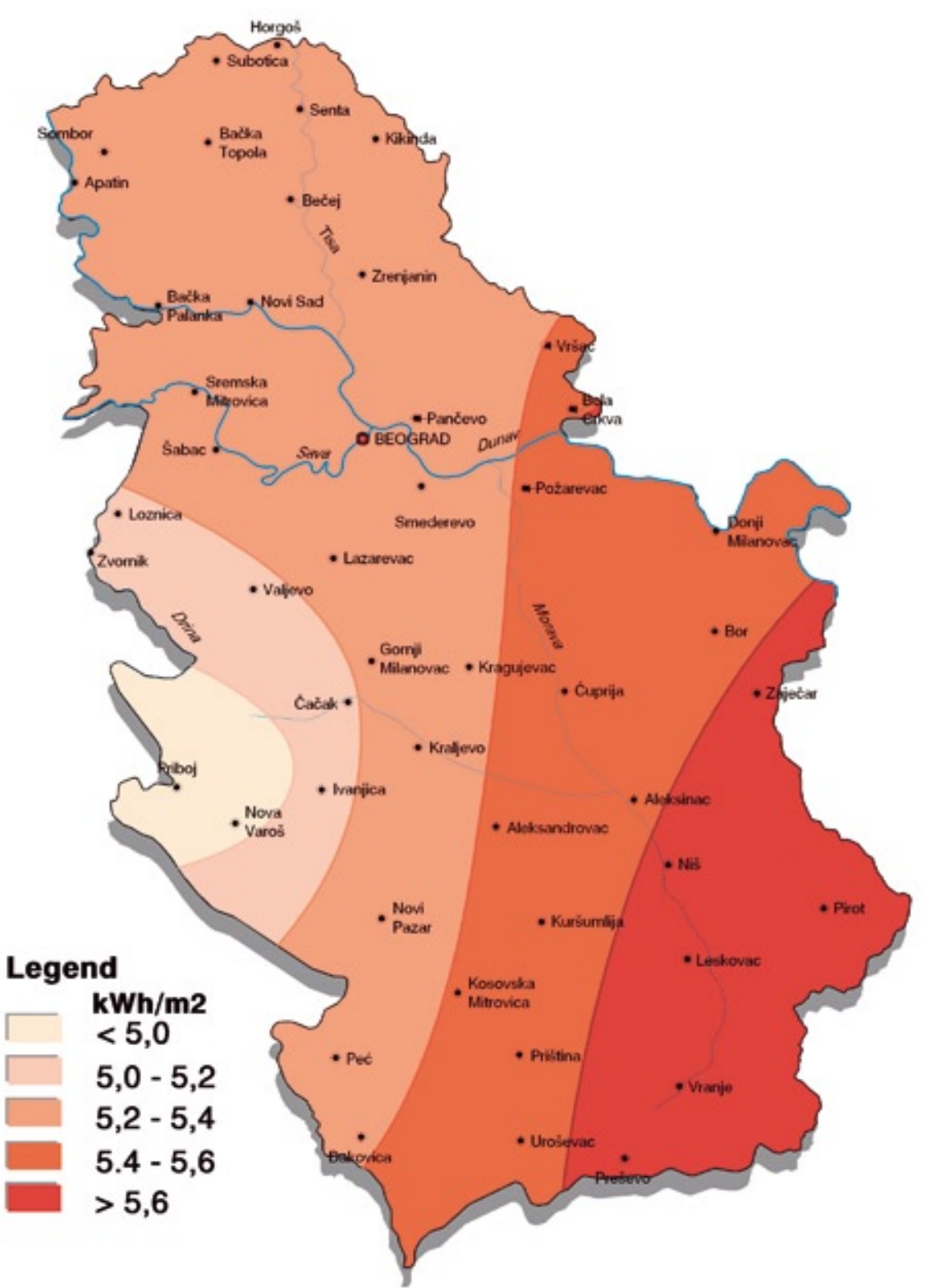

Figure 1 Map of daily average of global solar energy on horizontal plane in Serbia for vegetation period (April - September) from 1961. to 1990.

men and Golubac, and Smederevska Palanka and Zrenjanin, has been identified as the windiest part of Serbia. There are also some mountainous regions with considerable wind energy potential. The data, displayed in Figure 2, indicate that wind power in Danube river valley region in the winter months (the heating season from October to March) exceeds 500 W/ $\mathrm{m}^{2}$. There are also some mountainous regions with a considerable wind energy potential, as well.

\section{Solar and Wind Energy Complementarity}

Both solar and wind energy are highly intermittent electricity generation sources. Time intervals within which these fluctuations occur span multiple temporal scales, from seconds to years. There are periodic and non-periodic fluctuations. Base period is either one day (diurnal fluctuations) or one year (annual fluctuations). Non-periodic fluctuations are related to the weather change (Gburčik V, et al, 2006). Only annual periodic fluctuations will be presented herein.

Figure 3 shows annual distribution of solar and wind energy density $\left(\mathrm{kWh} / \mathrm{m}^{2}\right)$ according to measurements taken at the Meteorological Station "Zeleno Brdo" in Belgrade. Note that the solar energy is being measured per square meter of horizontal surface, while the wind energy is being measured per square meter of rotor area (vertical area swept by the turbine blade), according to EU standard methodology (CEC, 1989).

The solar energy ratio between December and July is 1:6.1. The wind energy ratio between July and March (or November) is approximately 1:2.75. The ratio between aggregated solar and wind energy over the period August-September and that over the period March-April is 1:1.8. In other 


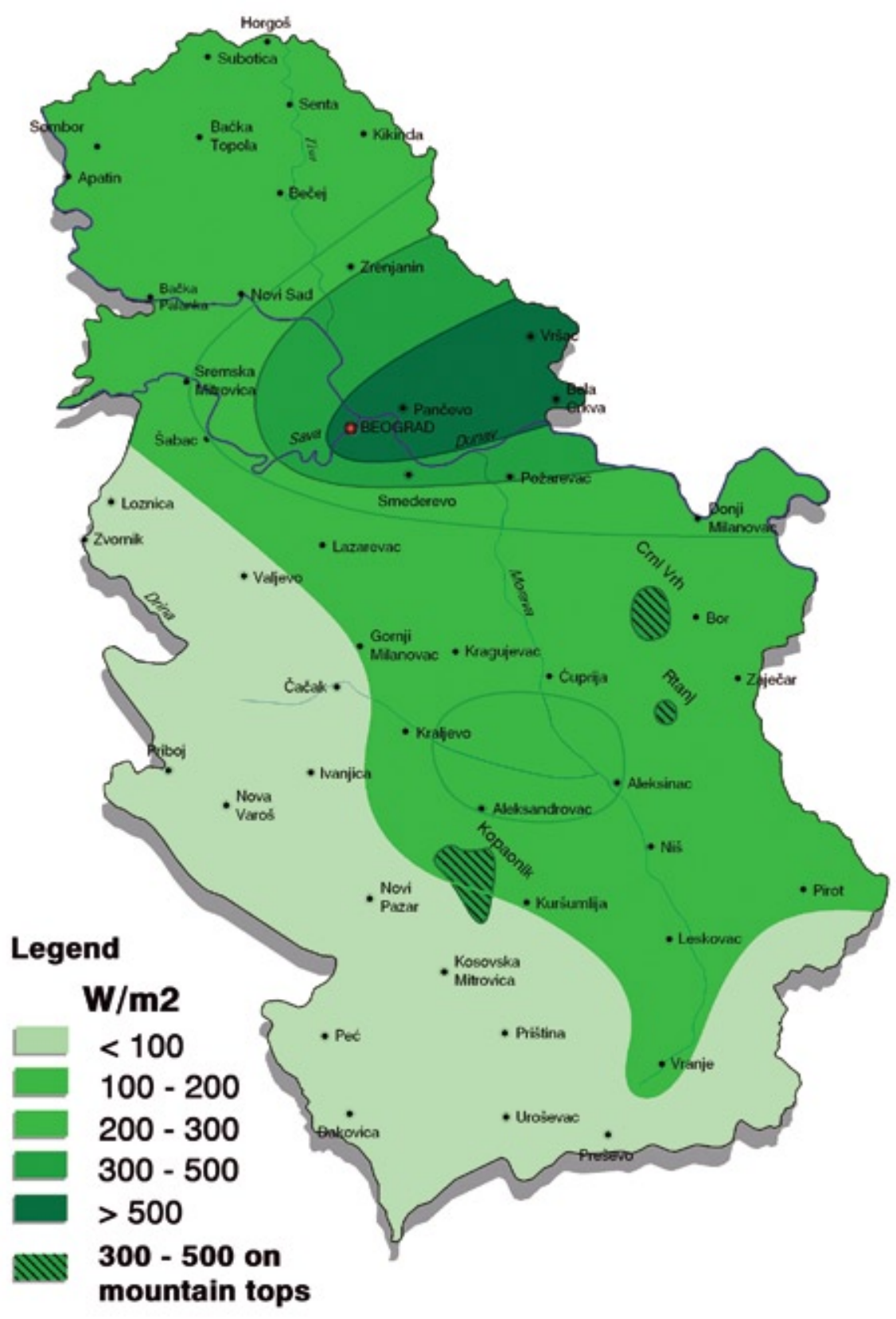

Figure 2 Map of average wind power at the height of 10om in Serbia for heating period (October - April) from 1961. to 1990.

words, relative fluctuation of solar energy influx over the year can be compensated by adding wind energy, thus decreasing the ratio from 1:6.1 to 1:1.8. The effects of complementarity are even more dramatic if nocturnal periods (absence of solar radiation) or the periods of "adverse" weather conditions (typically, reduced solar radiation and strong

\section{The Economics of Wind Energy}

As it was pointed out in the introduction, the cost of energy being produced by contemporary wind turbines is already lower than that produced from natural gas (UNEP, 2002b), (Awerbuch, 2006).

The wind energy system, like all renewable and advanced energy systems, is characterized by generally high initial investment but low operation and maintenance costs. Associated expenses comprise of the cost of wind turbine, its operation and maintenance, as well as the cost of grid maintenance. At this point the cost of $1 \mathrm{~kW}$ of installed wind turbine capacity is up to $€ 1,000$ (EU, 2006b). The cost per $\mathrm{m}^{2}$ of the rotor area depends on the local wind energy availability. Operational costs also vary between countries and between wind farm sites.

\section{City of Belgrade as an example}

Annual energy consumption per capita for Belgrade metropolitan area is $1,700 \mathrm{kWh} /$ $\mathrm{m}^{2}$ (ZIS_BGD, 2005). Wind energy at elevation of $100 \mathrm{~m}$ above the ground for the same area amounts to some $4,000 \mathrm{kWh}$ annually per square meter of rotor area (Figure 3). Assuming a conservative estimate of wind turbine efficiency of $20 \%$, the annual yield of electric energy amounts to $800 \mathrm{kWh} / \mathrm{m}^{2}$. Consequently, to satisfy total energy needs of Belgrade entirely from wind sources, it suffices to install around 2 square meters of rotor area per capita; which, expressed in terms of a cost per square meter of rotor area, amounts to some $€ 500 / \mathrm{m}^{2}$.

Therefore, the required investment in wind turbines for Belgrade metropolitan area would be about $€ 1,000$ per capita. It is important to note at this point that individual investments in wind turbines have some practical limitations. The calculations above have been made for wind turbines with turbine axes at $100 \mathrm{~m}$ above the ground, where wind energy is several times higher than at, say, $10 \mathrm{~m}$ above the ground. Furthermore, due to large fluctuations in wind power, one cannot get a steady supply of electric energy from a small wind turbine. For one thing, that would imply the need to accumulate the excess energy when it occurs which may prove to be prohibitively expensive. Connecting to power grid provides for steady and stabile supply of electric energy, while allowing for ex-

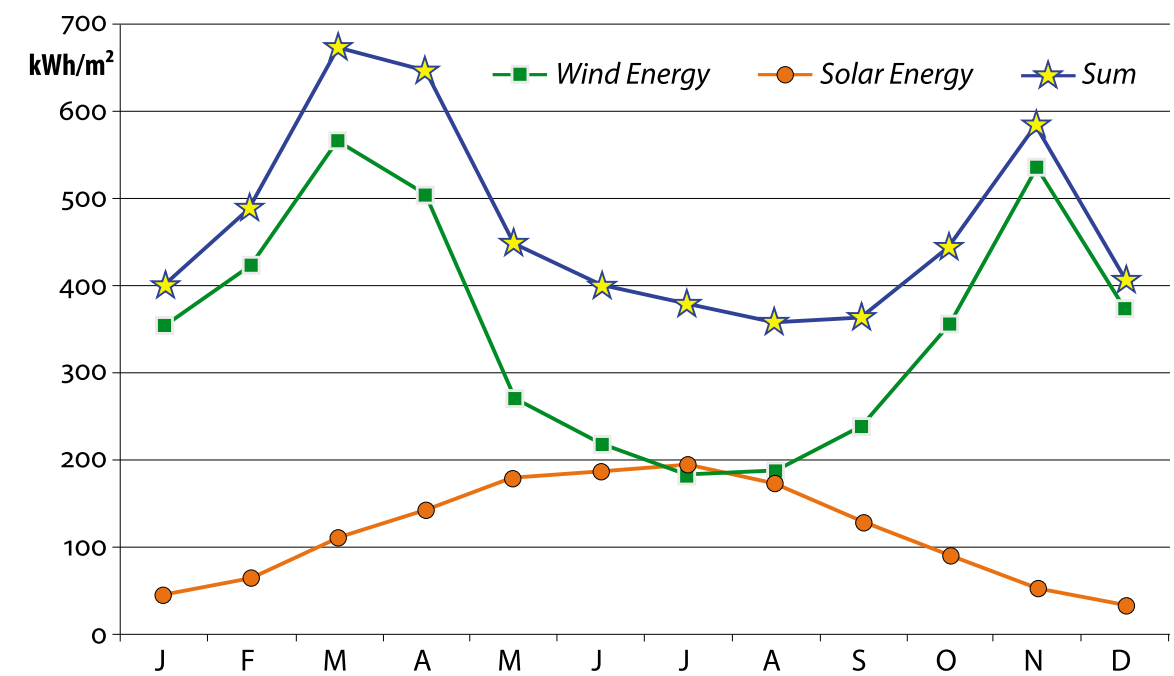

Figure 3 Annual of average (by month) course of solar and wind energy in Belgrade from 1961. to 1990. (Wind at the height of 10om, solar at the surface) 
cess energy produced by wind turbine to be fed into the grid. In other words, it is the large systems that are in this case more efficient.

\section{Conclusions}

Amount of energy available from renewable (climatic) sources is, beyond a doubt, large enough to completely substitute fossil and nuclear energy fuels. It is open to discussion as to what strategy and tactics would best pave the way of return to use of climatic energy resources, which are the only warrant of the long-term sustainable development and survival of life on Earth. There is not only long-term but also immediate strong motivation for countries with no fossil fuel resources of their own to secure their energy independence.

Transition to renewable energy resources has been hampered in part by the fact that economic advantage has not been sufficiently clear. Government support for conventional energy sector obscures their real electricity generation costs. When discussing economic aspects, the environmental and health benefits are usually not been accounted for. Recent economic research shows that, even if environmental and health benefits are being ignored, wind energy is already at this point less expensive than that obtained from natural gas.
There are some countries with more modest climatic resources than Serbian, where solar and wind energy is converted into electric energy end fed into the public grid, thus increasing the system's capacity and efficiency.

An inherent problem with climatic resources is that of periodic and non-periodic fluctuations. We have demonstrated in this study how the effects of these fluctuations can be reduced significantly by $\mathrm{cu}-$ mulative and complementing use of both solar and wind energy.

\section{References}

Awerbuch, S. 2006. Wind Economics in 21st Century. New Energy - Magazine for Renewable energy, No.1/o6, European Renewable Energies Federation, Berlin, pp. 44-47.

CEC 1989. European Wind Atlas. Commission of the European Communities, Brussels, $656 \mathrm{p}$.

EU 2003. Programme 2003-2006 «Intelligent Energy for Europe». Decis. 1230/2003/EC of EU Parliament, 37 p.

EU 2006a. EU Energy Policy Data. Comm. of the European Communities, Brussels, $74 \mathrm{p}$.

EU 2006b. New and Renewable Energies, Photovoltaics: Objectives - Technologies. http://europa.eu.int, $3 \mathrm{p}$.

EWEA 2006. European record for wind power: over 6,000 MW installed in
2005 - Wind energy has surpassed EC White Paper targets for 2010. News Release, 1/2006, European Wind Energy Association, Brussels, $2 \mathrm{p}$.

Gburčik P. et al. 2004. Study of Energy Potential of Serbia for Utilizing Solar Radiation and Wind Energy". 271 p. (In Serbian) [Avalable from the Center for Multidisciplinary Studies University of Belgrade Kneza Viseslava 1, 11030 Belgrade and Ministry for Science and Environmental Protection, Nemanjina 26, 11000 Belgrade]

Gburčik V. et al. 2006. Variability of Solar Radiation and Atmospheric Ozone - Trends and Impacts. Archiv Pharm. 56, 131-139.

Mays, I. 2006. European Energy Crisis The No Fuel Solution Wind Economics in 21st Century. New Energy - Magazine for Renewable energy, No.1/o6, European Renewable Energies Federation, Berlin, pp. 4.

UNEP 2002a. Sustainable Energy Programme. UNEP Division of Technology, Industry and Economics, Paris, $4 \mathrm{p}$.

UNEP 2002b. Solar and Wind Energy Resource Assessment (SWERA). UNEP Division of Technology, Industry and Economics, Paris, $20 \mathrm{p}$.

ZIS_BGD 2005. Statistical Yearbook of Belgrade. Institute of Informatics and Statistic, Belgrade, 365 p. (in Serbian). 